\title{
Osteoporoz Nedeniyle Başvuran ve Homosistinüri Tanısı Alan iki Kardeş: Olgu Sunumu
}

\section{Two Siblings With Osteoporosis and Homocystinuria: Case Report}

\author{
Betül BAKAN, Ali Murat KALENDER*, Mehmet ÇifTSÜREN, Metin KILIÇ** \\ Kahramanmaraş Sütçü Imam Üniversitesi Tıp Fakültesi, Fizik Tedavi ve Rehabilitasyon Anabilim Dalı, Kahramanmaraş, Türkiye \\ *Kahramanmaraş Sütçü Imam Üniversitesi Tıp Fakültesi, Ortopedi ve Travmatoloji Anabilim Dalı, Kahramanmaraş, Türkiye \\ **Kahramanmaraş Sütçü Imam Üniversitesi Tıp Fakültesi, Biyokimya Anabilim Dalı, Kahramanmaraş, Türkiye
}

\section{Özet}

Kemiğin yapım yıkım oranının bozulması veya kemik mikromimarisinde rol alan matriks ve bağ yapısındaki bir bozukluk osteoporozla sonuçlanabilir. Homosistinüri metionin metabolizmasında rol oynayan enzimlerin defektine bağlı, birçok sistemle birlikte kas-iskelet sistemini de etkileyen, herediter geçişli bir hastalıktır ve erken yaştaki sekonder osteoporoz sebeplerinden biridir. Sırt ağrısı ve osteoporoz nedeniyle polikliniğimize başvuran, daha önce Marfan Sendromu tanısı almış erişkin iki kardeşe fizik muayene ve laboratuar bulgularıyla homosistinüri tanısı kondu. Ölgular erken yaştaki osteoporozda homosistinüri gibi kemik metabolizmasını etkileyen metabolik hastalıkların ayırıcı tanıda akılda tutulmasını vurgulamak amacıyla sunuldu. Türk Fiz Tip Rehab Derg 2013;59:76-8.

Anahtar Kelimeler: Osteoporoz, homosistinüri, metionin

\section{Summary}

Decreased bone turnover or a defect in the structure of the matrix and connective tissue in bone microarchitecture can result in osteoporosis. Homocystinuria is a hereditary disorder due to defects of enzymes involved in the metabolism of methionine which affects the musculoskeletal system as well as other systems. Homocystinuria is one of the causes of secondary osteoporosis seen at early ages. Two adult siblings, who have been previously diagnosed with Marfan's syndrome, presented with back pain and osteoporosis. The diagnosis of homocystinuria was established based on physical examination and laboratory findings. In this paper, we present these cases in order to emphasize that metabolic disease like homocystinuria should be kept in mind in the differential diagnosis of osteoporosis seen in early age group. Turk J Phys Med Rehab 2013;59:76-8. Key Words: Homocystinuria, osteoporosis, methionine

\section{Giriş}

Osteoporoz, kemik kütlesinde azalma ve kemik dokusunun mikro-mimarisinde bozulma sonucu kemik kırılganlığında artış ile karakterize bir iskelet sistemi hastalığıdır (1-3). Osteoporozun etiyopatogenezinin ve eşlik eden risk faktörlerinin bilinmesi hastalığın gelişiminin önlenmesi, erken tanı ve tedavisinde önemlidir.

Metabolik hastalıklar osteoporoz etiyolojisinde rol oynamaktadır. Homosistinüri, metionin metabolizması bozukluğuna bağlı, herediter geçişli bir metabolizma hastalığıdır. Di-eter metionini sistationine çeviren enzimlerden sıklıkla da sistationin $\beta$-sentaz defektinden dolayı doğumdan itibaren kanda ve idrarda hem metionin, hem de sülfürlü bir aminoasit olan homosistein düzeyleri $\operatorname{artar}(4,5)$.
Homosisteinin plazma konsantrasyonunun yükselmesi sinir, kas-iskelet, göz, solunum ve kardiyovasküler sistem gibi birçok organda yaygın doku hasarı yapar. İskelet sisteminde osteoporoz, skolyoz, dolikostenomeli, epifizlerde genişleme, pektus karinatum veya ekskavatum gibi çeşitli kemik deformiteleri ve marfonoid görünüme sebep olabilir (14). Osteoporozun nadir görülen sebeplerinden biridir $(4,5)$.

Bu makalede, osteoporozla gelen ve daha önce tanı konmamış homosistinürili erişkin iki kardeş sunuldu. Bu yazıda erken yaştaki osteoporozun etiyolojisinde homosistinüri gibi metabolik hastalıkların akılda tutularak ayırıcı tanıda düşünülmesinin vurgulanması amaçlandı.

Yazışma Adresi/Address for Correspondence: Dr. Betül Bakan, Kahramanmaraş Sütçü İmam Üniversitesi Fiziksel Tıp ve Rehabilitasyon Anabilim Dalı, Kahramanmaraş, Türkiye Tel.: +90344221 2337 E-mail: berdembakan@gmail.com 


\section{Olgu 1}

Yirmi dokuz yaşında erkek hasta, osteoporoz ilaç raporunu yeniletmek için polikliniğimize başvurdu. Annesi, hastanın üç yıl önce osteoporoz tanısı aldığını 1 yıl nazal kalsitonin, 2 yıl bifosfonat kullandığını ifade etti. Özgeçmişinde yürümeye 1,5 yaşında, konuşmaya 3 yaşında başladığı ve 6 yaşında göz ameliyatı geçirdiği, gözüne lens takılması gerektiği ama takılamadığı, geç çocukluk döneminde Marfan sendromu tanısı aldığı, ilköğretim çağında özel rehabilitasyon merkezinde eğitim aldığı, 6 yıl önce epilepsi başladığı, 4 yıl önce beyin damarlarında tıkanma olduğu (o dönemde çekilen kraniyal manyetik rezonans ve kraniyal venografide sağ transvers superior sagital sinüs trombozu saptanmış) ve halen antikoagülan, antiepileptik ve osteoporoz ilaçları kullandığı öğrenildi. Soygeçmişinde, annebaba arasında birinci dereceden akrabalık olduğu, kız kardeşinde ve iki kuzeninde de kendisiyle benzer fiziksel görünüm ve yakınmalar olduğu öğrenildi.

Başvuru sırasında yapılan fizik muayenede vital bulgular stabil, genel durum iyi, bilinci açık, koopere olarak tespit edildi. Kas-iskelet sistemi muayenesinde hasta marfonoid görünümde, boyu 1,84 cm, ektremiteleri uzun, kifotik postürde, vertebralar palpasyonla ağrılı olup başka patolojik bulgu saptanmadı. Santral sinir sistemi muayenesinde hafif mental retardasyon saptandı, solunum sistemi ve gastrointestinal sistem muayenesi doğal olarak değerlendirildi, kardiyovasküler sistem muayenesinde her iki bacakta varisler tespit edildi. Göz muayenesinde her iki gözde geçirilmiş lens operasyonuna ve miyopa bağlı görme bozukluğu tespit edildi; hastanın 6 yaşından beri gözlük kullandığı annesi tarafından ifade edildi.

Kemik mineral yoğunluğu (KMY) dual enerji X-Ray absorbsiyometri yöntemi (Hologic QDR-4500A model) (DXA) kullanılarak ölçüldü. Lomber vertebra KMY T skoru -3,8; Z skoru -3,8; total femur KMY T skoru -1,5; Z skoru -1,4 (osteopeni) olarak bulundu, spinal osteoporoz olarak değerlendirildi. Çekilen dorso-lomber grafilerde vertebralarda osteoporotik çökme kırıkları tespit edildi (Resim 1).

Laboratuvar incelemelerinde hemogram, AST, ALT, üre, kreatinin, paratiroid hormon, kortizol, total testesteron, TSH, serbest T3, serbest T4, alkalen fosfataz, kalsiyum, fosfor normal değerlerde bulundu. Plazma vitamin B12 düzeyi $<150 \mathrm{pg} / \mathrm{mL}$ (N: 193-982 pg/mL), folik asit düzeyi 2,84 ng/mL (N: 3-17 ng/ $\mathrm{mL}$ ) olarak normalden düşük bulundu.

\section{Olgu 2}

İlk olgunun kız kardeşi olan 21 yaşındaki kadın hasta sırt ağrısı nedeni ile polikliniğimize başvurdu. Özgeçmişinde 2 yaşında yürüdüğü, 4 yaşlarında konuşmaya başladığı ama halen düzgün konuşamadığı, 8 yaşında gözlerinden ameliyat olduğu ve mercek takıldığı, 2 yı önce romatizmal kalp hastalığı geçirdiği, bu sebeple kardiyoselektif $\beta 1$-reseptör blokeri, antihipertansif ve penisilin kullandığı (ekokardiyografi: romatizmal kalp hastalığı ve 2/4 mitral yetmezlik), normal ilköğretime kabul edilmediği, halen özel rehabilitasyon okuluna gittiği öğrenildi.

Yapılan fizik muayenede; vital bulgular stabil, genel durum iyi, bilinci açık, koopere idi. Kas-iskelet sistemi muayenesinde hasta marfonoid görünümde, boyu $1,81 \mathrm{~cm}$, ekstremiteleri uzun ve dorsal vertebralar palpasyonla ağrılı bulundu. Postür analizinde dorsolomber skolyoz tespit edildi (Resim 2). Santral sinir sistemi muayenesinde hafif mental retardasyon ve kelimeleri tam çıkaramamasına bağlı konuşma bozukluğu saptandı. Solunum sistemi ve gastrointestinal sistem muayenesi doğal olarak değerlendirildi, kardiyovasküler sistem muayenesinde mitral kapak yetmezliğine bağlı 2/6 şiddetinde üfürüm tespit edildi. Göz konsültasyonu sonucu her iki gözde geçirilmiş lens operasyonuna ve miyopa bağlı görme bozukluğu tespit edildi; hastanın 8 yaşından beri gözlük kullandığı annesi tarafından ifade edildi.

Çekilen vertebra grafisinde skolyoz ve kemik mineral yoğunluğunda azalma tespit edildi. Yapılan DXA incelemesinde, lomber KMY T değeri -1,7; Z değeri -1,5; total femur KMY T değeri 0,$4 ; Z$ değeri 0,4 olarak ölçüldü, spinal osteopeni olarak değerlendirildi.

Laboratuvar incelemelerinde hemogram, AST, ALT, üre, kreatinin, paratiroid hormon, kortizol, östrojen, progesteron, TSH, serbest T3, serbest T4, alkalen fosfataz, kalsiyum, fosfor, folik asit normal değerlerde bulundu. Vitamin B12 $150 \mathrm{pg} / \mathrm{mL}$ (N: 193-982 pg/mL) olup, normalden düşük bulundu. Öykü ve fizik inceleme özellikleri ile hastaların düşük KMY'lerinin etiyopatogenezinde homosistinüri olabileceği düşünülerek plazma homosistein ve metionin seviyesi ölçüldü. Birinci olgunun plazma homosistein ve metionin düzeyi sırasıyla $359 \mu \mathrm{mol} / \mathrm{L}(\mathrm{N}: 5-12 \mu \mathrm{mol} / \mathrm{L})$ ve $39,65 \mathrm{nmol} / \mathrm{ml}(\mathrm{N}: 12-32$ $\mathrm{nmol} / \mathrm{ml})$, ikinci olgunun homosistein seviyesi $333 \mu \mathrm{mol} / \mathrm{L}$ (N: $5-12 \mu \mathrm{mol} / \mathrm{L}$ ) ölçüldü. Íkinci olguda teknik sebeplerden dolayı metionin düzeyi çalışılamadı.

Birinci olguya öykü, klinik ve laboratuar bulgularıyla klasik homosistinüri ve homosistinüriye bağlı osteoporoz tanısı konularak, metioninden fakir diyet, folik asit, B6-B12 vitamini, betain, kalsiyum, D vitamini ve bifosfanat başlandı. İkinci olguya klasik homosistinüri ve homosistinüriye bağlı osteopeni tanısı konularak, metioninden fakir diyet, B6-B12 vitamini, betain, kalsiyum ve D vitamini preparatı başlandı. Her iki olguya, osteoporoz egzersizleri ve postür egzersizleri önerildi.

\section{Tartışma}

Homosistinüri otozomal resesif geçiş gösteren, 1/100.000200.000 sıklığında görülen, multisistemik bir metabolizma hastalığıdır. Metionin metebolizmasında rol alan enzimlerin eksikliği sonucu oluşur. Çoğunlukla sistationin sentaz enziminde eksiklik mevcuttur. Plazmada metionin ve homosistein seviyelerinin yüksek olması ve idrarda homosistein atılımının artmasıyla tanı konur $(5,6)$. Normal açlık plazma homosistein düzeyleri 5-15 $\mu \mathrm{mol} / \mathrm{L}$ arasındadır. 16-30 $\mu \mathrm{mol} / \mathrm{L}$ düzeylerinde artışlar hafif, 31-100 $\mu \mathrm{mol} / \mathrm{L}$ düzeylerinde artışlar orta, 100 $\mu \mathrm{mol} / \mathrm{L}$ üzerinde artışlar ise ciddi homosistinemi olarak kabul edilir $(8,9)$. Bizim olgularımızın plazma homosistein düzeyleri $359 \mu \mathrm{mol} / \mathrm{L}$ ve $333 \mu \mathrm{mol} / \mathrm{L}$ olup ciddi homosistinemi olarak kabul edildi.

Hastalığın klinik prezentasyonu defektif olan enzime, serum homosistein ve metioninin seviyesine göre farklılık gösterir. Homosisteinin plazma konsantrasyonunun yükselmesi sinir, kas-iskelet, göz, solunum ve kardiyovasküler sistem gibi birçok organda yaygın doku hasarı yapar. Hastalığın kliniğinde marfanoid görünüm, mental reterdasyon, nöbetler, 
göz anomalileri, vasküler tromboz ve iskemi sıklıkla görülür (10). Zaidi ve ark. (11) yaşları 2 ile 31 arasında değişen 22 homosistinürili hastanın 15'inde mental problemler, 15'inde lens subluksasyonu, 10'unda orta veya ciddi skolyoz, 8 hastada osteoartrit, eklem kontraktürü, genu valgus, Legg-CalvePerthes, sindaktili gibi kas-iskelet sistemi problemleri ve bir hastada superior sagital sinüs trombozu bildirmişlerdir. Burada sunulan her iki olguda da mental reterdasyon, göz anomalileri, kifoskolyoz; ayrıca ilk olguda epilepsi ve geçirilmiş superior sagital sinüs trombozu saptandı.

Homosistinüri uzun boy, uzun ekstremite, ektopik lens, kas-iskelet anomalileri sebebiyle laboratuvar testleri ile ekarte edilmezse Marfan Sendromu ile karışabilir $(12,13)$. Oladipo ve ark. (12) 53 yaşında homosistinüri tanısı alan, daha önce yanlış olarak Marfan Sendromu tanısını konmuş bir olgu sunmuşlardır. Franchis ve ark. (14) yayınladıkları 71 olgunun 35'inde Marfanoid görünüm tespit etmişlerdir. Bizim olgularımız da Marfanoid görünümde olup, geç çocuklukta Marfan sendromu tanısı almışlardı.

Kalıtsal homosistinüride KMY azalmakta ve yaşa göre osteoporoz görülme olasılığı \%50 oranında artmaktadır $(10,13)$. Kalıtsal homosistinüride gelişen osteoporozun mekanizması hakkındaki genel görüş homosisteinin (Hcy) kollajenin solubilite ve stabilitesi için gerekli çapraz bağların oluşumunu bozduğu şeklindedir (15). Çapraz bağ yapısının bozulması kollajenin daha kolay yıkılmasına neden olabilir. Ayrıca son yıllarda yapılan çalışmalar, yeterli mineralizasyon için kemik matriks yapısının özellikle önemli olduğunu göstermektedir Dolayısıyla, çapraz bağ yapılarının Hcy ile bozulması, kemik matriks yapısının ve mineralizasyonun bozulmasına ve dolaylı olarak da osteoporoza katkıda bulunabilir $(10,16)$. Ayrıca, Hcy'nin osteoblast fonksiyonlarını bozduğu (17), osteoklast aktivitesini arttırdığı bildirilmiştir (18). Franchis ve ark. (14) 71 homosistinürili hastanın \%45'inde, Zaidi ve ark. (11) da 22 homosistinürili hastanın \%36,3'ünde osteoporoz tespit etmişlerdir. Biz de birinci olguda vertebra kırıklı ciddi osteoporoz, ikinci olguda osteopeni saptadık.

Homosistinürinin tedavisinde düşük metioninli diyet, metionin metabolizmasında rol alan enzimlerin kofaktörü olan B12, B6 ve folik asit vitaminleri ve diyeti yeterli uygulayamayan hastalarda homosisteinin remetilasyonunu sağlayan betain kullanılmaktadır $(5,13)$. Bu şekilde kanda homosistein seviyesi normal sınırlara çekilerek hastalığın komplikasyonlarının önüne geçilmesi hedeflenmektedir. Benzinger (13) 44 yaşında disk hernisi ile başvuran, çekilen radyografilerinde osteoporoz tespit edilen ve yapılan tetkikler sonucu homosistinüri tanısı alan hastaya düşük metioninli diyet, B6-B12 vitamini, folik asit, bifosfanat, kalsiyum ve $D$ vitamini tedavisi uygulamıştır.

Biz de her iki olguya düşük metioninli diyet, B6-B12 vitamini, folik asit, betain, kalsiyum ve D vitamini başladık, osteoporoz egzersizleri ve postür egzersizleri önerdik, ek olarak osteoporozlu birinci olgunun tedavisine bifosfonat ilave edildi.

Sonuç olarak, erken yaşta osteoporozla gelen ve multisistem tutulumu olan hastaların etiyopatogeneze yönelik araştırılmalarında homosistinüri gibi metabolik hastalıklar akılda tutulmalıdır. Homosistinürinin erken tanısı ve tedavisi komplikasyonların gelişimini önleyebilir.

\section{Çıkar Çatışması}

Yazarlar herhangi bir çıkar çatışması bildirmemişlerdir.

\section{Kaynaklar}

1. Sinaki M. Osteoporosis. In: Braddom RL, editor. Pysical Medicine and Rehabilitation. Philadelphia: W.B Saunders Company; 2000. p. 894-912.

2. Arasıl T. Günümüzde Osteoporoz. Kutsal YG, editör. Osteoporoz Cep Kitabı. 1. Baskı. Ankara: Güneş Kitabevi; 2005. s. 1-8.

3. Erhan B, Gündüz B. Postmenopozal osteoporotik kadınlarda fraktürün yaşam kalitesi üzerine etkisi. Osteoporoz Dünyasından 2006;12:31-4.

4. Özlem S, Samancı N, Karayalçın B, Bilgilisoy M, Gürbüz Ü, Illliez ÖG, ve ark. Postmenopozal osteoporoz ve osteopenide plazma homosistein düzeyleri ile biyokimyasal kemik döngüsü belirteçleri arasındaki ilişki. Osteoporoz Dünyasından 2006;12:22-6.

5. Mudd SH, Levy HL, Kraus JP. Disorders of transsulfuration. In: Scriver CR, Beaudet AL, Sly WS, Vale D,editors. The Metabolic and Molecular Bases of Inherited Disease. 8th ed. McGraw Hill Company; 2001. p. 2007-56.

6. Behrman RE, Kliegman RM, Jenson HB. Nelson Textbook of Pediatrics. 16th ed. Philadelphia: W.B. Saunders Co; 2000. p. 351.

7. Finkelstein JD. Methionine metabolism in mammals. J Nutr Biochem 1990;1:228-37.

8. Kang SS, Wong PWK. Hyperhomocystinemia as a risk factor for occlusive vascular disease. Ann Rev Nutr 1992;12:279-98.

9. Weiss N, Keller C, Hoffmann U, Loscalzo J. Endothelial dysfunction and atherothrombosis in mild hyperhomocysteinemia. Vasc Med 2002;7:227-39.

10. Khan M, Yamauchi M, Srisawasdi S, Stiner D, Doty S, Paschalis $E P$, et al. Homocysteine decreases chondrocyte-mediated matrix mineralization in differentiating chick limb-bud mesenchymal cell micro-mass cultures. Bone 2001;28:387-98.

11. Zaidi SH, Faiyaz- UI-Haque M,Shuaib T, Balobaid A, Rahbeeni Z, Abalkhail $H$, et al. Clinical and molecular findings of 13 families from Saudi Arabia and a family from Sudan with homocystinuria. Clin Genet 2012;81:563-70.

12. Oladipo O, Spreitsma L, Dietzen DJ, Shinawi M. Increased homocysteine in a patient diagnosed with marfan syndrome. Clin Chem 2010;56:1665-8.

13. Benzinger $P$, Alscher DM. Untreated homocystinuria in adulthood. Dtsch Med Wochenschr 2005;130:2439-43.

14. Franchis RD, Sperandeo MP, Sebastio G, Andria G. The Italian collaborative study group on homocystinuria clinical aspects of cystathionine beta-synthase deficiency: how wide is the spectrum? Eur J Pediatr 1998;157:67-70.

15. Reiser K, McCormick R, Rucker R. Enzymatic and nonenzymatic cross-linking of collagen and elastin. FASEB J 1992;6:2439-49.

16. Paschalis EP, Shane E, Lyritis G, Skarantavos G, Mendelsohn R, Boskey AL. Bone fragility and collagen cross-links. Bone Miner Res 2004;19:2000-4.

17. Sakamotoa W, Isomuraa H, Fujiea K, Deyama Y, Kato A, Nishihira $\mathrm{J}$, et al. Homocysteine attenuates the expression of osteocalcin but enhances osteopontin in MC3T3-E1 preosteoblastic cells. Biochim Biophys Acta 2005;1740:12-6.

18. Herrmann M, Widmann T, Colaianni G, Colucci S, Zallone A, Herrmann W. Increased osteoclast activity in the presence of increased homocysteine concentrations. Clin Chem 2005;51:2348-53. 